\title{
Performance Assessment of Gas Turbine Power Plants
}

Ebigenibo Genuine Saturday ${ }^{*}$, Tamunobelema Justice Okumgba

Department of Mechanical Engineering, University of Port Harcourt, Nigeria

DOI: $10.36348 /$ sjet.2020.v05i06.002

| Received: 06.05.2020 | Accepted: 24.05.2020 | Published: 18.06 .2020

*Corresponding author: Ebigenibo Genuine Saturday

\section{Abstract}

This work presents the performance assessment of two industrial gas turbine power plants. The plants are GE M5001 gas turbine and BBC M05864 gas turbine, all operated in Rivers state, Nigeria. The international standard organization (ISO) rating, average operating field data and calculated results of the gas turbine performance parameters were compared. The first law analysis was employed for the calculations, where the exhaust gas temperatures, net power outputs and the thermal efficiencies were estimated. The calculations were done using the pressure ratios obtained from the field for the M5001 turbine, while the ISO value was used for the M05864 turbine. The maximum and minimum power generated as obtained from the field during the period of study are $20.37 \mathrm{MW}$ and $19.15 \mathrm{MW}$ respectively, obtained at pressure ratios of 8.33 and 7.87 respectively, while the corresponding calculated values are $24.44 \mathrm{MW}$ and $24.17 \mathrm{MW}$ respectively for the M5001 turbine. The corresponding thermal efficiency values calculated are $27.09 \%$ and $26.79 \%$ respectively. The ISO rating of the turbine is $26.84 \mathrm{MW}$, the thermal efficiency is $28.4 \%$ while the pressure ratio is 10.5 . For the M05864 turbine, the ISO pressure ratio of 9.55 was used for the calculations. The calculated power output is $50.196 \mathrm{MW}$ as against the field value of $50 \mathrm{MW}$. The ISO rating is much higher at $65 \mathrm{MW}$. There is thus no much difference in the net power output between the field data and the calculated value for the M05864 turbine, but there is significant difference in this parameter for the M5001 turbine. The ISO values are generally higher because the real engines operate at higher ambient temperatures. The comparisons between the calculated values and the field results reveal how well the engines are being operated.

Keywords: Pressure ratio, Ambient temperature, Exhaust gas turbine, Power output, Thermal efficiency.

Copyright @ 2020: This is an open-access article distributed under the terms of the Creative Commons Attribution license which permits unrestricted use, distribution, and reproduction in any medium for non-commercial use (NonCommercial, or CC-BY-NC) provided the original author and source are credited.

\section{INTRODUCTION}

The gas turbine is an internal combustion engine and has three basic components which are compressor (C), combustion chamber (CC) and turbine. The ambient atmospheric air which is the working fluid of the gas turbine is drawn into the circuit continuously and compressed by the compressor. Gas turbine power plants plays a key role to meet the need of power generation [1]. The gas turbine power plants among different kinds of power plants for power generation gains more attention due to its low capital cost to power ratio, high flexibility, high reliability without complexity, compactness, early commissioning and commercial operation and fast starting-accelerating and quick shut down [1]. Generation of power depends on the sufficiently available energy source in a particular region. Nigeria has the world's ninth proven gas reserves $(\sim 180,105 \mathrm{bscf})$ [2]. Hence, gas is the primary energy source for power generation in Nigeria. 25 gridconnected power plants located largely in the Niger Delta region has $85 \%$ of installed capacity generated by gas thermal power plants (22) and the remaining $15 \%$ is generated by hydroelectric power plants (3). The plants are run by generation companies including those formerly under the Power Holding Company of Nigeria (PHCN), National Integrated Power Project (NIPP) and Independent Power Producers (IPPs).

Noting the need for substantial power generation, power plant performance assessment is necessary to understand accurately the operation of the various units [3]. Gas turbine operates efficiently when working under its engine design points (International Organization of Standardization, ISO conditions) configurations and at various component optimum performance levels [4]. This paper compares the ISO rating of gas turbine and the average operating data of gas turbine over a period of 90 days (July to September 2019). This exercise is carried out in this research using the General Electric (GE) M5001 model of a gas turbine at the Trans-Amadi power station, and Brown Boveri Company (BBC) M05864 model of a gas turbine at the Afam power station, both in the Niger 
Delta region of Nigeria. The study is centered on the energetic analysis of the gas turbine.

Many researchers have looked at gas turbine performance and factors affecting engine performance $[5,6]$. The performance evaluation of gas turbine power plant in order to ascertain its suitability as option for power generation in the region has been studied [7]. The limitation and possible solution to the optimum performance of gas turbine has also been studied [1, 811]. Using energy and exergy analysis the performance of gas turbine was analyzed [12]. The variation of engine operating conditions on performance parameters was also studied in Reference [13] and results similar to those of related works were obtained. It was observed that gas turbine plant losses $0.1 \%$ of its thermal efficiency and $1.47 \mathrm{MW}$ of its total power output when ambient temperature increases by $1 \mathrm{~K}$ above ISO condition [10]. Many other authors have carried out performance analysis based on operating parameter of gas turbine and the variation from the ISO parameters $[14,15]$. Although, there are several works on performance assessment of gas turbine power plants, but such analysis has not been extended to the plants used as a case studies viz-a-viz comparing the results of the operating data and ISO parameters.

\section{METHODOLOGY}

Engineering performance analysis of the simple cycle plant based on the first law of thermodynamics will be carried out. Operating data obtained from the field will be used to calculate the thermal efficiency and power output of the gas turbine and comparison will be made with the ISO parameters of the gas turbine retrieved from the manufacturer's manuals. The performance analysis is simplified with the usage of the T-s diagram in Figure 1(a).

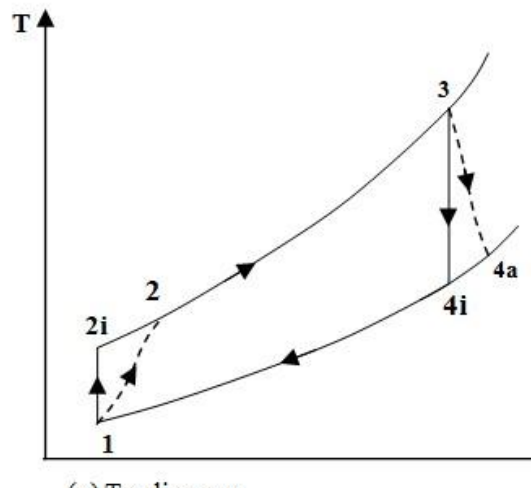

(a) T-s diagram

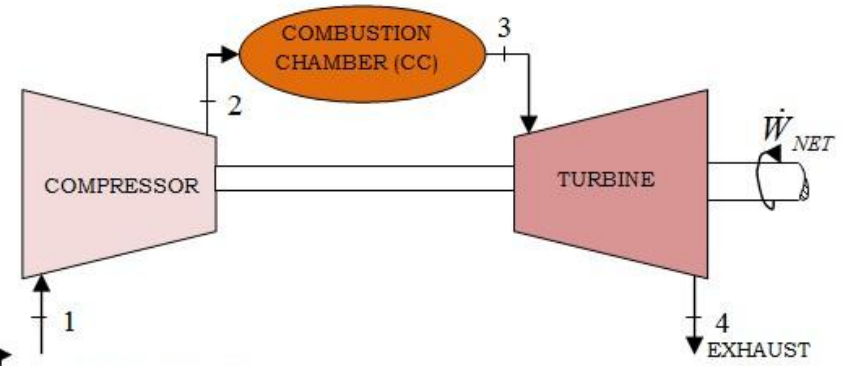

(b) Block diagram

Fig-1: Temperature-entropy (T-s) and block diagrams of a real GT engine cycle [16]

From the $\mathrm{T}$-s diagram, process $1-2 \mathrm{i}$ is the isentropic compression, process $1-2 \mathrm{a}$ is the actual compression, and process $3-4 \mathrm{i}$ is isentropic expansion while process $3-4 \mathrm{a}$ is the actual expansion. The thermal efficiency $\eta_{\text {th }}$ of the cycle is given as,

$$
\eta_{t h}=\frac{\dot{W}_{N E T}}{\dot{Q}_{\text {in }}}=\frac{\dot{W}_{t}-\dot{W}_{c}}{\dot{Q}_{\text {in }}}
$$

Where $\dot{W}_{n e t}$ is the net power output of the cycle, $\dot{W}_{t}$ is the turbine power output, $\dot{W}_{c}$ is the power consumed by the compressor and $\dot{Q}_{i n}$ is the rate of heat input into the cycle. The power consumed by the compressor is,

$$
\dot{W}_{c}=\dot{m}_{a} c_{p, a}\left(T_{2 a}-T_{1}\right)
$$

Where $\dot{m}_{a}$ is the air flow rate, $c_{p, a}$ is the specific heat capacity of air, $T_{2 a}$ is the actual temperature at the compressor exit and $T_{1}$ is the temperature at the inlet of the compressor, assumed to be the ambient temperature. $T_{2 a}$ relates with the ideal temperature at the compressor exit $T_{2 i}$ in the form,

$$
T_{2 a}=T_{1}+\frac{T_{2 i}-T_{1}}{\eta_{c, i}}
$$

Where $\eta_{c, i}$ is the isentropic efficiency of the compression process, accounting for the compression losses. The value of $\eta_{c, i}$ can be obtained from Equation (4) based on only the PR [17]

$$
\eta_{c, i}=1-\left(0.04+\frac{r_{p}-1}{150}\right)
$$

Where $r_{p}$ is the PR across the turbine. The ideal temperature at the compressor exit is given as,

$$
T_{2 i}=T_{1}\left(r_{p}\right)^{\frac{\gamma_{a}-1}{\gamma a}}
$$

Where $\gamma_{a}$ is the ratio of specific heat capacities of air. The power produced by the turbine is given by Equation (6),

$$
\dot{W}_{t}=\dot{m}_{a} c_{p, g}\left(T_{3}-T_{4 a}\right)
$$

Where $c_{p, g}$ is the specific heat capacity of the flue gases and $T_{4 a}$ is the actual temperature of the gases at the turbine exit. $T_{4 a}$ relates with the ideal temperature at the turbine exit $T_{4 i}$ in the form,

$$
T_{4}=T_{3}-\eta_{T, i}\left(T_{3}-T_{4 i}\right)
$$

Where $\eta_{t, i}$ is the isentropic efficiency of the expansion process, accounting for the expansion losses. 
Ebigenibo Genuine Saturday \& Okumgba Tamunobelema Justice., Saudi J Eng Technol, June, 2020; 5(6): 265-270

The value of $\eta_{t, i}$ can be obtained from Equation (8) based on only the PR [17],

$$
\eta_{T, i}=1-\left(0.03+\frac{r_{p}-1}{180}\right)
$$

The ideal temperature at the turbine exit is given as,

$$
T_{4 i}=T_{3}\left(r_{p}\right)^{\frac{1-\gamma_{g}}{\gamma g}}
$$

Where $r_{p}$, is the turbine PR and $\gamma_{g}$ is the ratio of the specific heat capacity of the flue gases, taken as 1.33 in this work. The heat input into the cycle $Q_{\text {in }}$ comes from the burning of the fuel, natural gas in this case. This is given as,

$$
Q_{i n}=\dot{m}_{f} H_{f} \eta_{c c}
$$

Where $\dot{m}_{f}$ is the mass flow rate of fuel, $H_{f}$ is the lower calorific value of the fuel and $\eta_{c c}$ is the combustion efficiency. The value of the combustion efficiency was assumed to be $98 \%$ in this work. The turbine entry temperature, TET $\left(T_{3}\right)$ can be estimated by considering energy balance in the $\mathrm{CC}$ thus,

$\dot{m}_{a} c_{p, a} T_{2}+\dot{m}_{f} H_{f} \eta_{c c}=\left(\dot{m}_{a}+\dot{m}_{f}\right) c_{p, g} T_{3}$

By design, part of the air flow is extracted towards the end of the combustion process and used for cooling the turbine blades. It is assumed that the amount of air extracted for blade cooling equals the fuel flow rate. When that is considered, the energy balance in the $\mathrm{CC}$ will be in the form,

$$
\begin{gathered}
\dot{m}_{a} c_{p, a} T_{2}+\dot{m}_{f} H_{f} \eta_{c c}=\left(\left|\dot{m}_{a}-\dot{m}_{f}\right|+\dot{m}_{f}\right) c_{p, g} T_{3} \\
\left.\dot{m}_{a} c_{p, a} T_{2}+\dot{m}_{f} H_{f} \eta_{c c}=\dot{m}_{a} c_{p, g} T_{3} \ldots \ldots \ldots \ldots \ldots . . .112\right)
\end{gathered}
$$

The turbine entry temperature is thus given as, $T_{3}=\frac{\dot{m}_{a} c_{p, a} T_{2}+\dot{m}_{f} H_{f} \eta_{c c}}{\dot{m}_{a} c_{p, g}}$
The specific heat capacity of the flue gases assuming ideal gas mixture in the $\mathrm{CC}$ can be expressed as,

$$
\begin{aligned}
& c_{p, g}=x_{a} c_{p, a}+x_{f} c_{p, f} \\
& x_{f}=\frac{\dot{m}_{f}}{\dot{m}_{t}} \ldots \ldots \ldots \ldots \ldots \ldots \ldots \ldots \\
& x_{a}=1-x_{f} \ldots \ldots \ldots \ldots \ldots
\end{aligned}
$$

Where $c_{p, f}$ is the specific heat capacity of the fuel, $x_{f}$ and $x_{a}$ are the mass fractions of fuel and air respectively and $\dot{m}_{t}$ is the total mass flow rate. $\dot{m}_{t}$ is considered to be equal to $\dot{m}_{a}$ since an equivalent of $\dot{m}_{f}$ is extracted for blade cooling in the $\mathrm{CC}$ outlet.

The specific heat capacity of air can be expressed as a function of temperature as [18], $c_{p, a}=0.9706+0.006791 \times 10^{-2} T+0.01658 \times 10^{-5} T^{2}-$ $0.0679 \times 10^{-9} T^{3}$

The specific heat capacity of fuel (natural gas which consists mostly methane) $c_{p, f}$ can be expressed as [18],

$c_{p, \mathrm{CH}_{4}}=1.243+0.314 \times 10^{-2} \mathrm{~T}+0.0793 \times 10^{-5} T^{2}-$ $0.688 \times 10^{-9} T^{3}$

Considering the gas mixture in the $\mathrm{CC}$, it can be observed that $c_{p, a}$ and $c_{p, f}$ are functions of $T_{3}$. Hence solving for $T_{3}$ and $c_{p, g}$ involves using iterative method. This was carried out in this work using Microsoft Excel Solver.

\section{RESULTS AND DISCUSSIONS}

The ISO rating of the gas turbines which were retrieved from the manufacturer's manuals are presented in Table-1, where ambient temperature is $15^{\circ} \mathrm{C}(288 \mathrm{~K})$ and the ambient pressure is $1 \mathrm{~atm}$ (1.01325bar).

Table-1: ISO rating of the gas turbines

\begin{tabular}{|l|l|l|l|l|}
\hline Parameter & Symbol & \multirow{2}{*}{ Unit } & Value & \\
\cline { 4 - 5 } & & & M5001 & M05864 \\
\hline Ambient temperature & $T_{1}$ & $\mathrm{~K}$ & 288 & 288 \\
\hline Compressor outlet temperature & $T_{2}$ & $\mathrm{~K}$ & 593 & 619 \\
\hline Turbine inlet temperature & $T_{3}$ & $\mathrm{~K}$ & 1216 & 1218 \\
\hline Turbine outlet temperature & $T_{4}$ & $\mathrm{~K}$ & 748 & 758 \\
\hline Exhaust gas temperature & $T_{e x h}$ & $\mathrm{~K}$ & 748 & 758 \\
\hline Compressor inlet pressure & $P_{1}$ & $\mathrm{bar}$ & 1.01325 & 1.01325 \\
\hline Inlet pressure loss & $P_{\text {loss }}$ & $\mathrm{bar}$ & 0.004663 & $\mathrm{n} / \mathrm{a}$ \\
\hline PR & $r_{p}$ & - & 10.5 & 9.55 \\
\hline Mass flow rate of fuel & $\dot{m}_{f}$ & $\mathrm{~kg} / \mathrm{s}$ & 1.84 & 3.65 \\
\hline Exhaust gas flow & $\dot{m}_{a}$ & $\mathrm{~kg} / \mathrm{s}$ & 125.2 & 247 \\
\hline Efficiency & $H$ & $\%$ & 28.4 & $\mathrm{n} / \mathrm{a}$ \\
\hline Power output & $P O$ & $\mathrm{MW}$ & 26.83 & 65 \\
\hline
\end{tabular}

The average field data of the gas turbines for period of 90 days (July - September 2019) are presented in Table-2. The data was gotten from the monitoring chart of the control room in the power stations. Only parameters of concerned were taken. Table-3 present other basic operating parameters for the analysis of the gas turbines of which the percentage pressure loss in the $\mathrm{CC}$, the percentage pressure loss in the exhaust and the combustion efficiency are assumptions within the common practice range of $5,4.5$ and 98 percent 
Ebigenibo Genuine Saturday \& Okumgba Tamunobelema Justice., Saudi J Eng Technol, June, 2020; 5(6): 265-270

respectively. The ambient temperature on the average in the region is $27^{\circ} \mathrm{C}(300 \mathrm{~K})$ and the lower heating value of the fuel is taken to be $49000 \mathrm{~kJ} / \mathrm{kg}$ for M5001 and
$48948.3 \mathrm{~kJ} / \mathrm{kg}$ for M05864. The calculated outputs of the gas turbines are presented in Table-4. The PR obtained from the field was used for the calculations.

Table-2: Average operating data of the gas turbines

\begin{tabular}{|l|l|l|l|l|l|l|}
\hline \multirow{2}{*}{ Parameter } & \multirow{2}{*}{ Symbol } & \multirow{2}{*}{ Unit } & \multicolumn{3}{|l|}{ Value } & \\
\cline { 4 - 7 } & & & \multicolumn{2}{|l|}{ M5001 } & M05864 \\
\cline { 4 - 7 } & & & Jul. & Aug. & Sept. & Jul. - Sept. \\
\hline Power output & $\mathrm{PO}$ & MW & 19.15 & 19.61 & 20.37 & 50 \\
\hline Exhaust gas temperature & $\mathrm{T}_{4}$ & $\mathrm{~K}$ & 756.9 & 742.5 & 746.6 & 728 \\
\hline Compressor outlet pressure & $\mathrm{P}_{2}$ & bar & 7.97 & 8.32 & 8.44 & 9.67 \\
\hline
\end{tabular}

Table-3: Basic operating parameters of the gas turbines

\begin{tabular}{|l|l|l|l|l|}
\hline Parameter & \multirow{2}{*}{ Symbol } & \multirow{2}{*}{ Unit } & \multicolumn{2}{|l|}{ Value } \\
\cline { 4 - 6 } & & & M5001 & M05864 \\
\hline Ambient temperature & $\mathrm{T}_{1}$ & $\mathrm{~K}$ & 300 & 300 \\
\hline Ratio of specific heat capacity of air & $\gamma_{a}$ & - & 1.4 & 1.4 \\
\hline Ratio of specific heat capacity of flue gas & $\gamma_{g}$ & - & 1.33 & 1.33 \\
\hline Percentage pressure loss in the CC & $\mathrm{x}_{\mathrm{c}}$ & $\%$ & 5 & 5 \\
\hline Percentage pressure loss in the exhaust & $\mathrm{x}_{\mathrm{e}}$ & $\%$ & 4.5 & 4.5 \\
\hline Combustion efficiency & $\eta_{\mathrm{cc}}$ & $\%$ & 98 & 98 \\
\hline Lower heating value of natural gas & $\mathrm{H}_{\mathrm{f}}$ & $\mathrm{kJ} / \mathrm{kg}$ & 49000 & 48948.3 \\
\hline
\end{tabular}

Table-4: Calculated outputs of the gas turbines

\begin{tabular}{|c|c|c|c|c|c|c|}
\hline \multirow[t]{3}{*}{ Parameter } & \multirow[t]{3}{*}{ Symbol } & \multirow[t]{3}{*}{ Unit } & \multicolumn{3}{|l|}{ Value } & \multirow{3}{*}{$\begin{array}{l}\text { M05864 } \\
\text { Jul. - Sept. }\end{array}$} \\
\hline & & & \multicolumn{3}{|l|}{ M5001 } & \\
\hline & & & Jul. & Aug. & Sept. & \\
\hline Compressor PR & $r_{p}$ & - & 7.87 & 8.21 & 8.33 & 9.55 \\
\hline Isentropic efficiency of the compressor & $\eta_{c, i}$ & - & 0.9142 & 0.9119 & 0.9111 & 0.903 \\
\hline Ideal compressor outlet temperature & $T_{2 i}$ & $\mathrm{~K}$ & 540.90 & 547.47 & 549.75 & 571.64 \\
\hline Actual compressor outlet temperature & $T_{2 a}$ & $\mathrm{~K}$ & 563.51 & 571.37 & 574.11 & 600.82 \\
\hline Actual power consumed by the compressor & $\dot{W}_{c}$ & MW & 33.156 & 34.146 & 34.489 & 74.674 \\
\hline Mass fraction of fuel & $x_{f}$ & - & 0.0147 & 0.0147 & 0.0147 & 0.0148 \\
\hline Mass fraction of air & $x_{a}$ & - & 0.9853 & 0.9853 & 0.9853 & 0.9852 \\
\hline Specific heat capacity of compressor outlet gas & $c_{p, a}$ & $\mathrm{~kJ} / \mathrm{kgK}$ & 1.1492 & 1.1503 & 1.1506 & 1.1545 \\
\hline Specific heat capacity of fuel & $c_{p, f}$ & $\mathrm{~kJ} / \mathrm{kgK}$ & 4.6420 & 4.6557 & 4.6605 & 4.7109 \\
\hline Specific heat capacity of flue gas & $c_{p, g}$ & $\mathrm{~kJ} / \mathrm{kgK}$ & 1.2005 & 1.2018 & 1.2022 & 1.2071 \\
\hline Turbine inlet temperature & $T_{3}$ & $\mathrm{~K}$ & 1059.56 & 1065.05 & 1066.96 & 1087.51 \\
\hline Head added into the gas turbine & $\dot{Q}_{\text {in }}$ & MW & 88.357 & 88.357 & 88.357 & 175.088 \\
\hline Combustor outlet pressure & $P_{3}$ & bar & 7.4765 & 7.7995 & 7.9135 & 9.23 \\
\hline Turbine outlet pressure & $P_{4}$ & bar & 1.045 & 1.045 & 1.045 & 1.045 \\
\hline Turbine PR & $r_{p}$ & - & 7.15 & 7.46 & 7.57 & 8.83 \\
\hline Isentropic efficiency of the turbine & $\eta_{t, i}$ & - & 0.9318 & 0.9299 & 0.9293 & 0.9225 \\
\hline Actual exhaust gas temperature & $T_{4 a}$ & $\mathrm{~K}$ & 738.16 & 740.11 & 739.81 & 720.68 \\
\hline Actual power produced by the turbine & $\dot{W}_{t}$ & MW & 57.327 & 58.522 & 58.931 & 124.869 \\
\hline Net power output & $\dot{W}_{n e t}$ & MW & 24.172 & 24.376 & 24.441 & 50.196 \\
\hline Thermal efficiency & $\eta_{t h}$ & $\%$ & 27.36 & 27.58 & 27.66 & 28.67 \\
\hline
\end{tabular}

The results show that the compressor PRs for July, August and September are 7.87, 8.21 and 8.33 respectively for M5001 and 9.55 for M05864. The PRs impacts on the other parameters of the gas turbines- the increase observed in the PRs can also be seen in both the ideal and actual compressor outlet temperature and the actual power consumed by the compressor. Also, the same increase and effect is observed for the turbine PRs. The parameters impacted directly are both the ideal and actual exhaust gas temperature and actual power produced by the turbines. It is also observed that the compressor PRs are greater than that of the respective turbine PRs which is obtainable due to the pressure losses in the turbine. The net power output of the gas turbine for each of the three months is 24.172MW, 24.376MW and 24.441MW respectively for M5001 and 50.196MW for M05864. The increase observed is obtained from the subsequent effect of the PRs which have similar increase. The thermal efficiency also experiences same increase which values 
are $27.36 \%, 27.58 \%$ and $27.66 \%$ respectively for M5001 and $28.67 \%$ for M05864. It is also worthy of note that the TET for each month which are 1059.56K, $1065.05 \mathrm{~K}$ and $1066.96 \mathrm{~K}$ respectively for M5001 and $1087.51 \mathrm{~K}$ for M05864 are also contributing factor to the increase in thermal efficiency.
Table-5 presents a comparison between the ISO ratings, the field values and the calculated values of some parameters of the gas turbines.

Table-5: Comparison of performance parameters

\begin{tabular}{|c|c|c|c|c|}
\hline \multirow[t]{2}{*}{ Result type } & \multicolumn{3}{|l|}{ M5001 } & \multirow{2}{*}{$\begin{array}{l}\text { M05864 } \\
\text { Jul. - Sept. }\end{array}$} \\
\hline & Jul. & Aug. & Sept. & \\
\hline \multicolumn{5}{|l|}{ PR $\mathbf{r}_{\mathbf{p}}(-)$} \\
\hline ISO rating & 10.5 & 10.5 & 10.5 & 9.55 \\
\hline Field data & 7.87 & 8.21 & 8.33 & 9.55 \\
\hline Calculated output & 7.87 & 8.21 & 8.33 & 9.55 \\
\hline \multicolumn{5}{|c|}{ Exhaust gas temperature T4 (K) } \\
\hline ISO rating & 748 & 748 & 748 & 758 \\
\hline Field data & 756.9 & 742.5 & 746.6 & 728 \\
\hline Calculated output & 738.16 & 740.11 & 739.81 & 720.68 \\
\hline \multicolumn{5}{|c|}{ Net power output $\dot{\mathbf{W}}_{\text {NET }}(\mathrm{MW})$} \\
\hline ISO rating & 26.83 & 26.83 & 26.83 & 65 \\
\hline Field data & 19.15 & 19.61 & 20.37 & 50 \\
\hline Calculated output & 24.172 & 24.376 & 24.441 & 50.196 \\
\hline \multicolumn{5}{|c|}{ Thermal efficiency $\eta_{\mathrm{th}}(\%)$} \\
\hline ISO rating & 28.4 & 28.4 & 28.4 & $\mathrm{n} / \mathrm{a}$ \\
\hline Calculated output & 27.36 & 27.58 & 27.66 & 28.67 \\
\hline
\end{tabular}

The comparison involves four parameters - PR which is a key input data, exhaust gas temperature, net power output and thermal efficiency. There is no field data for thermal efficiency, although this could be estimated from the power output values and fuel flow rate (if provided). Also, there is no thermal efficiency of the M05864 turbine at ISO condition as the operators could not lay hands on the catalogues of this old engine, and the engine model is not available on the net. The PR obtained from the field was used for the calculations; hence the field values and the computations are compared on similar scale. For the M05864 model, the PR from the field was not available. Thus, the ISO value was used for the computations. More appropriate comparison is thus obtained with the M5001 turbine. The operating pressure ratios for the M5001 turbine for the three months are all lower than the ISO value. For the exhaust gas temperature, the calculated values are the lowest, followed by the field values except for the first month for M5001 turbine where the field value is greater than the ISO value. This is likely an error from the temperature probes. For fixed TET, the exhaust gas temperature will increase with the $\mathrm{PR}$, but that is not the case here where more heat input occurred at higher PR values as in Table 4. Obviously, the turbines in the field go with lower fuel flow rate and hence lower TET leading to lower exhaust gas temperatures. The ISO rating exhaust gas temperature is greater than the respective calculated exhaust gas temperature because of the lower pressure ratios employed in the calculations.
As the engines in the field operate at lower pressures and higher ambient temperatures, the ISO rating net power output values are greater than the respective calculated as well as field values. Also, net power output from the field is less than the corresponding calculated value, with more pronounced difference observed in the M5001 turbine. The later indicates that smaller turbines are more affected by ambient conditions. The lower field values indicate that the turbines have suffered more losses than those assumed for the computations. The power output increases with the PR for the three months considered for the M5001 turbine. The thermal efficiencies calculated are smaller than the ISO value for the M5001 turbine, and follows similar trend as the net power output. Comparing the field and calculated power outputs from the two turbines, the M05864 turbine is operating better than the M5001 turbine with percentage difference between the field and computed values of $0.392 \%$ and $19.99 \%$ respectively.

\section{CONCLUSIONS}

Performance assessment of industrial gas turbines was carried out in this work. The power output and thermal efficiency of the gas turbines are strongly influenced by the PR, ambient temperature and the turbine entry temperature. High PR and high turbine inlet temperature produces high power output and thermal efficiency. The comparison of performance parameters (PR, exhaust gas temperature, power output and thermal efficiency) showed the variation between the ISO rating, field data and calculated output of the 
Ebigenibo Genuine Saturday \& Okumgba Tamunobelema Justice., Saudi J Eng Technol, June, 2020; 5(6): 265-270

gas turbines. There is no much difference in the net power output between the field data and the calculated value for the M05864 turbine, but there is significant difference in this parameter for the M5001 turbine. This implies that the M05864 turbine in the field is operating properly, while the M5001 turbine has suffered much degradation or losses than those assumed for the calculations. There is much difference between the field data and the ISO ratings of both plants under study. The variation of the field data from the ISO ratings is based on the fact that operating conditions differ from design condition. Accurate prediction of the performance of the real engine in the field is necessary. This will aid in the procurement of turbines by not depending on the ISO rating but estimated performance parameters. With this, the actual power output in the field can be obtained and the number of units to be installed to meet the power demand requirement can be obtained.

\section{REFERENCES}

1. Oyedepo, S. O., Fagbenle, R. O., Adefila, S. S., \& Adavbiele, S. A. (2014). Performance evaluation and economic analysis of a gas turbine power plant in Nigeria Energy Convers. Manag. 79, 431440.

2. [2] Nigeria Advisory Power Team. (2015). Nigeria Power Baseline Report 36, Available in: www.nesistats.org, Accessed on March 18, 2020.

3. Green, D. W., \& Perry, R. H. (2007). Perry's Chemical Engineers' Handbook, Eighth Edition, McGraw-Hill, NY.

4. Walsh, P. P., \& Fletcher, P. (2004) Gas Turbine Performance, $2^{\text {nd }}$ ed., Blackwell Publishing Company, Oxford.

5. Abam, F. I., Ugot, I. U., \& Igbong, D. I. (2011). Thermodynamic Assessment of Grid-Based Gas Turbine Power Plants in Nigeria. Journal of Emerging Trends in Eng Appl Sci. (JETEAS), 2(6):1026-1033.

6. Ejenavi, O. W. (2018). Performance Analysis Of Gas Turbine Power (A Case Study Of Delta III GT9 Transcorp Gas Turbine Power Plant, Ughelli, Nigeria). Global Scientific Journal, 6(6):44-55.

7. Ademusuru, P. O., Ogunedo, M. B., \& Okoro, V. I. (2017). Performance Evaluation of Gas Turbine
Plant in Niger Delta Region of Nigeria: A Case Study of Afam Power Plant Elixir Mech. Engg. 108, 47419-47422.

8. Bédécarrats, J. P., \& Strub, F. (2009). Gas turbine performance increase using an air cooler with a phase change energy storage. Appl Therm Eng. 29, 1166-1172.

9. Kim, Y. S., Lee, J. J., Kim, T. S., \& Sohn, J. L. (2011), Effects of syngas type on the operation and performance of a gas turbine in integrated gasification combined cycle Energy Convers. Manag. 52, 2262-2271.

10. De Sa, A., \& Al Zubaidy, S. (2011). Gas turbine performance at varying ambient temperature. Appl Therm Eng. 31, 2735-2739.

11. Farzaneh-Gord, M., \& Deymi-Dashtebayaz, M. (2011). Effect of various inlet air cooling methods on gas turbine performance Energy, 36, 1196-205.

12. Oyedepo, S. O., Fagbenle, R. O., Adefila, S. S., \& Alam, M. M. (2015). Performance Evaluation of Selected Gas Turbine Power Plants in Nigeria Using Energy and Exergy Methods. World J Eng. 12:161-176.

13. Lebele-Alawa, B. T., \& Jo-Appah, V. (2015). Thermodynamic Performance Analysis of a Gas Turbine in an Equatorial Rain Forest Environment. J Power Energy Eng. 3,11-23.

14. Rahman, M. M., Ibrahim, T. K., Kadirgama, K., Mamat, R., \& Bakar, R. A. (2011). Influence of Operation Conditions and Ambient Temperature on Performance of Gas Turbine Power Plant, $A d v$ Mater Res, 189-193.

15. Salim, B. (2017). Performance of a Gas Turbine Power Plant Int. J Mech Eng Appl. 5(1), 60-69.

16. Saturday, E. G., \& Orok, O. A. E. (2018), Comparative Exergo-Environmental Analysis of Simple and Regenerative Cycle Gas Turbine Plants, Scholars Journal of Engineering and Technology (SJET), 6(12), 432-443.

17. Alhazmy, M. M., \& Najjar, Y. S. H. (2004), Augmentation of Gas Turbine Performance Using Air Coolers, Appl. Therm. Eng. 24, 415-29.

18. Cengel, Y. A., \& Boles, M. A. (2009). Thermodynamics: An Engineering Approach, 5th ed., McGraw-Hill, NY. 